\title{
Erratum
}

\section{Interests, Issues, and Preferences: Women's Interests and Epiphenomena of Activism - ERRATUM}

\section{Karen Beckwith}

doi:10.1017/S1743923X11000195, Published by Cambridge University Press, 1 November 2011.

We regret that the originally published paper (Beckwith, 2011) did not contain the correct footnotes.

We apologize for this oversight and reproduce the author's footnotes below:

\section{THE CORRECTION}

From page 424, line 37:

I am grateful to Suzanne Dovi and Leslie Schwindt-Bayer for their helpful comments on the initial version of this essay.

From page 425, lines 77-80:

1 Among other interests that can be identified from women's self-organizing in contexts of relative autonomy and free deliberation are women's control of their reproductive capacity and bodily integrity; and women's personal and citizen autonomy, including freedom of mobility.

Published by Cambridge University Press 1743-923X/12 \$30.00 for The Women and Politics Research Section of the American Political Science Association.

(C) The Women and Politics Research Section of the American Political Science Association, 2012

doi:10.1017/S1743923X12000645 
2 To paraphrase Sen (1999: 10), women's interest in access to political power is not only a primary end; it is its principal means of achieving that end.

\section{REFERENCE}

Beckwith, Karen. 2011. "Interests, Issues, and Preferences: Women's Interests and Epiphenomena of Activism” Politics \& Gender 7 (3): 424-429. 